\title{
An Exploration Study of Rimballmu: A Qualitative Evaluation of Shared Single Display Groupware in Sarawak, Malaysia
}

\author{
http://dx.doi.org/10.3991/ijet.v10i1.4195 \\ WaiShiang C. ${ }^{1}$, Edwin $\mathrm{Mit}^{1}$, Marlene $\mathrm{Lu}^{2}$ \\ ${ }^{1}$ Universiti Malaysia Sarawak, Kota samarahan, Sarawak, Malaysia \\ ${ }^{2}$ Swinburne University, Kuching, Sarawak, Malaysia
}

\begin{abstract}
Shared single display groupware that enables collaboration among people from different cultures and social practices encourages peer learning and teaching, whilst strengthening communication skills. It has been successfully evaluated in remote schools in China and India. Due to this, the question arises whether it can be deployed in rural schools or semi-urban schools in Sarawak? What are the issues and challenges? What are the impact of this technology among the students and teachers? This paper investigates the deployment of shared single display groupware in rural and semi-urban schools in Sarawak (one of the Malaysian states). We introduce a shared single display application, Rimballmu, in one semi-urban school and one rural school and conduct qualitative analysis from the observations among the participants. Observational data has shown that RimbaIlmu is able to stimulate collaboration between different genders; an engaging technology among students; a tool for group and individual assessment; a tool to facilitate leadership skills; fun to play with; allows ease of lab management and control; enabling novices to learn computers; promoting membership in collaboration learning and finally provide environment for task accomplishment with minimum teacher intervention.
\end{abstract}

Index Terms - share single display

\section{INTRODUCTION}

Education technology heralds a new exploration to teaching innovation and learning experience in Malaysia. Education technology is defined as "the study and ethical practice of facilitating learning and improving performance by creating, using, and managing appropriate technological processes and resources" [20]. The introduction of technology into the education landscape is a catalyst to usher in a new paradigm in the teaching and learning process. Technology, coupled with the learning model to produce educational computer applications has transformed the pedagogical theories into the science of education.

Several technology-enhanced learning approaches have been introduced in the Malaysian education system. Lee $\mathrm{GH}$. et al. have introduced role playing games on mobile devices for learning History [8]. E-learning has been widely adopted Malaysian schools. Geography Information System, GIS is introduced for Geography lessons to teach the fundamentals to students. This, in turn creates the platform for the students to become spatial data analysts in the future. Studies have shown that GIS has positively influenced students' motivation to study Geography [21]. An interactive mobile game, LifeTree, was introduced by WaiShiang C. et al., 2013 to promote sustainable learning to the students of University Malaysia Sarawak (UNIMAS). It is a cause-effect mobile game in which a player needs to understand the cause of a pollution and the way to solve the problem.

The educational technologies that are discussed in the previous description are able to work in an ideal environment. It is always assumed that the technologies are deployed in a community that has constant power supply and reliable high-speed broadband Internet connectivity; students who own their own computers or smartphones with a mobile data plan; and sufficient and readily available technical support.

From our experience, such requirements are impractical in rural schooling environments or semi-urban schools. An interview was conducted with the primary school principal in Bario, a rural village located in the northeast of Sarawak. A brief account of the demographic of Bario is that it is populated by approximately 1000 people and the majority consists of the indigenous tribe known as the Kelabits [18]. From the interview, it was gathered that the current deployment of the education technologies is not sufficient for the usage in those schools. The lack of computer and networking facilities are among the main reasons that hamper the adoption of innovative technologies such as Rimballmu. Apart from that, the shortages of technical support, insufficient exploration time to use the education technologies have discouraged schools from employing such an approach.

Recognizing the need to balance between technology and the condition of the community, namely the context where it will be deployed, we propose that a Shared Single Display (SSD) groupware concept be implemented. SSD enables a group of users to share the same concurrent display (which can be a large display or just a monitor), where each member will have his or her own input device to simultaneously interact with the system. This allows collaborators to benefit from the advantages of face-toface interactions as they are co-located; as well as be able to observe the non-verbal communication among members such as excitement and enthusiasm of the collaborating parties.

This paper explores the potential usage of SSD groupware as education technology for remote and underprivileged schools. We introduce a prototype system, RimbaIlmu to allow students to interact with 
Bahasa Malaysia after school programme within a SSD. We conduct several pilot studies on Rimballmu in an education workshop and schools. We discuss the qualitative analysis and challenges and opportunities of SSD applications in resource constrained schools in Sarawak.

Section 2 provides a background study of a SSD groupware. This includes the learning model behind the SSD, collaborative learning and how the SSD groupware has been implemented in this study. Section 3 introduces the prototype developed for the SSD, known as RimbaIlmu. In this section, we also present the design of Rimballmu and its prototype view. Sections 4 and 5 present the qualitative evaluation of Rimballmu in improving the learning process of the students, respectively.. The final section examines the findings and provides discussion of the results, and the final section concludes the paper.

\section{BACKGROUND OF SDG}

Shared single display groupware enables many useful things such as collaboration among people from different cultures and social practice, enriching computer-based collaborations, encourages peer learning and peer teaching and strengthen communication skills [15]. A SSD groupware is a technology that advocates a single display unit and a single workstation to provide a collaborative learning environment for and among multiple participants concurrently. With this technology, each member will have his or her own input device to interact simultaneously with the system [3].

Mischief by Moraveji et al. [23] is a teaching system developed to enhance the social awareness among collocated students and supports interactions within a classroom with an instructor. Mischief enables students to interact simultaneously with their own respective mouse over a SSD. According to Moraveji et al., Mischief allows custom content creation. This is achieved by the instructor tagging the shape or object created in Microsoft PowerPoint indicating a particular Mischief behavior, and the application will then read and interpret the PowerPoint file with the use of the Audience Response System (ARS).

Alcoholado et al. [4] introduced the use of shared display in the learning of Mathematics. In their application, a mouse is allocated for the teacher who had privileged rights, enabling him/her to have active mediating roles and to intervene student's learning process. Students will identify themselves with their respective mice by going through an identification process. Each student will be given their own respective region on the screen and their cursor will be restricted to move only within their region. Students will then work on their individual region to solve given questions.

Until recently, the multipoint technology has evolved into more advance forms such as a multi-user mobile phone environment [14] and tabletop [13]. Tabletops provide a shared view of the task and a set of input devices to interface with the system [13]. However, tabletops are quite expensive and require high maintenance for local community. On the other hand, mobile devices such as smartphones have been used to control the cursor in a large shared display [14].

\section{RIMBAILMU}

Drawing from numerous sources on game-based SDG and adapting the themes and scenarios to the local context, RimbaIlmu was developed with multi-mice technology to enhance the learning of Malaysia's national language, Bahasa Malaysia (BM). Rimballmu is meant as an after school programme to allow the students to strengthen their knowledge of BM during their free time. It is targeted at year one primary school students. The content is derived based on the textbooks curriculum used in schools, enriched with visual elements. Figure 1 shows the main page of Rimballmu with a natural theme of Borneo Sarawak, which the students are familiar with and is visually engaging. Figure 2 shows the view of a SSD where players were participating in the activities through a shared big white screen.

Figure 3 shows one of the interaction styles during the activity session or also known as role-playing. In this design, one student assumes the role of a teacher and the other three become students. In the figure, the screen is split into four regions to provide a specific workspace for each user. Each user is confined within his own region. The main purpose is to eliminate interference between the workspaces in order to reduce confusion and interaction conflict. This is also to avoid visual clutter and occlusion [23]. Each mouse cursor is assigned with different icons

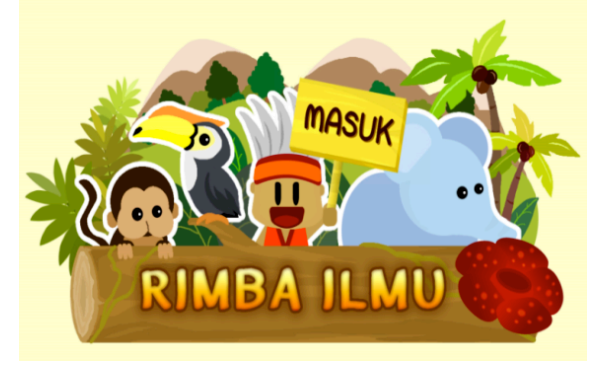

Figure 1. The main page of Rimba Ilmu

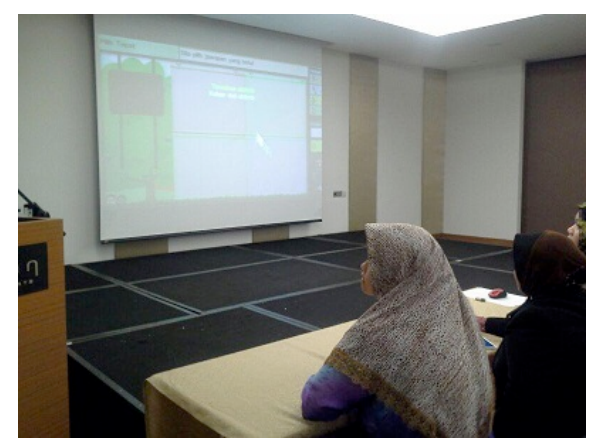

Figure 2. RimbaIlmu in a SSD environment

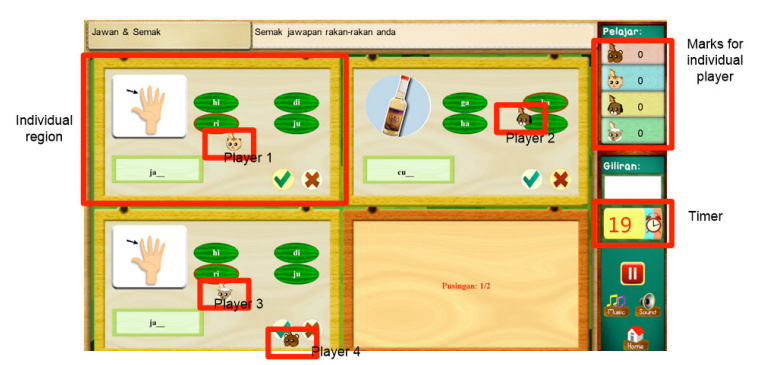

Figure 3. An activity in Rimballmu for SSD environment through intermediary interaction design. 
for easier cursor identification. For example, Player-1 is represented with the mouse cursor of a cat while Player-2 has a cursor of a dog. Player-3 is represented with the mouse cursor of a sheep which acts as a teacher in this activity. Player-4 is indicated by a bear cursor and is assigned with the teacher's role. It has the flexibility of moving across the regions to assess the answers from other players. The current version of Rimballmu supports three user input modes. They are shared keyboard, user input through drag and drop and mouse click.

Shared keyboard- The spelling test is one of the most common activities to test student's memorization skills by recalling words taught in the classroom. To spell the words, a soft keyboard is provided on the screen. As shown in Figure 4, the students are required to identify the image given and spell it out by selecting the right alphabets on the soft keyboard.

Figure 5 shows a Drag and Drop technique, where the players are required to choose the answers from the selections given at the bottom row of the screen and to drag their answer to the middle row in order to complete the word.

As for the clicking mode based on Figure 6, the player is required to select the right answer by clicking on the given options.

\section{OBSERVATION FROM PILOT STUDY}

Works have been done to conduct pilot testing for Rimballmu at three locations. The first pilot study was conducted at the International conference on teaching and learning through games. This was followed by two pilot studies in one rural school of Bario and one semi-urban school in Kota Samarhan.

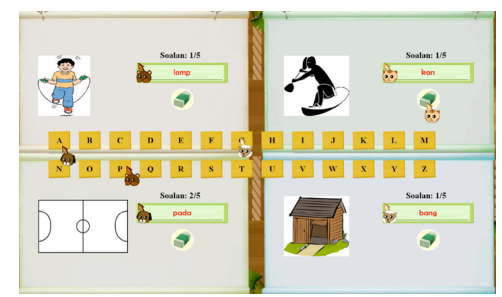

Figure 4. Screenshot on shared keyboard

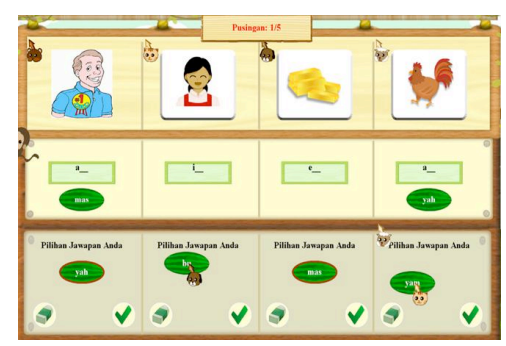

Figure 5. Screenshot on drag and drop

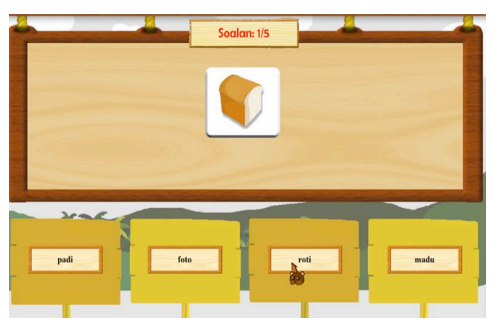

Figure 6. Screenshot onClick
In September, we conducted a workshop on testing the Rimballmu among the teachers and teachers' trainers at the International Conference on Teaching and Learning Through Games, ICoTLG, Kuching, Sarawak. The aim of this conference is to gather the teaching experts within the trainer's institutions, schools as well as NGOs.

It was a two days conference in which we presented the Rimballmu in a workshop session. The agenda for the 1.5hours workshop was as follows:

- To discuss the theories on Collaborative learning, Game-based learning, and Shared Single Groupware technology;

- To present the features of Rimballmu system;

- Rimballmu demonstration;

- Practicum with participants; and

- Gathering feedback and ideas for improvements.

The participants in the workshop possess a certain degree of ICT proficiency. The images in Figure 7 shows some of the participants of the workshop. Due to limited resources, we were only able to setup 3 groups of participants for the testing of Rimballmu. Participants were randomly grouped. Figure 8 shows the briefing and training of the Rimballmu. Excitement and enthusiasm were evident among the participants while the training was conducted.

After the practical trials of RimbaIlmu, questionnaires were distributed to the participants to obtain their feedbacks. Overall, Rimballmu received positive responses from the participants. The concept of SSD was widely accepted by the teachers and the teacher trainers. All the participants agreed on the usability of the system and said that it was easy for them to adapt to the technology. Meanwhile, almost all of the participants (98\%) did

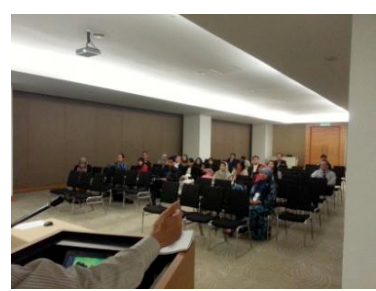

Figure 7. The participants (teachers, teacher trainers) attending the workshop;

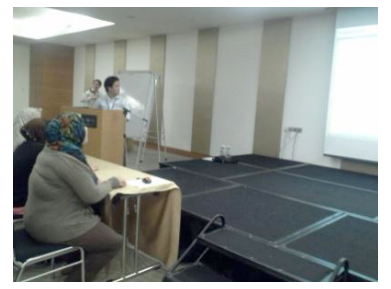

Figure 8. Training in using Rimballmu among the players

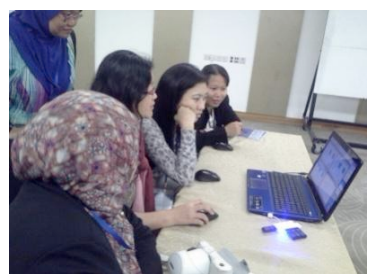

Figure 9. The participants are doing the hands-on exercises 
not resist the idea of adopting Rimballmu as an education technology. The interaction styles were also well received. Most of the participants were able to understand the requirements of the activities with ease. The splitting of a single display into different workspace with each assigned to a player provides a clear visual layout, reduces interference, confusion and interaction conflict. This has elevated the usability of the prototype and the ease of use.

From the open ended questions, we received the suggestions to improve our works as following.

Participant1-"Deploy RImbaIlmu in rural schools."

Participant2- "Explore Rimballmu with other subjects like Science and Mathematics."; "Promote the use of Rimballmu within a remote community during the discussion or meeting among their community."

Participant3- "Rimballmu needs to cover different disciplines of knowledge."

Participant4-"RimbaIlmu can be used for problembased learning."

Participant5- "We should control the number of mouse clicks to reduce confusion."

Participant6- "Instructions need to be clearer and more consistent."

\section{RimbaIlmu IN SCHOOLS}

A semi-urban school and a rural school were selected from different districts in Sarawak to evaluate RimbaIlmu. The first school is located at a semi urban area in Kota Samarahan, Sarawak. It is a small primary school which consists of less than 200 students. The school had just completed building a computer lab without any computer facilities. The students involved in the evaluation are literate where they know how to read, write and calculate. The second school is located at a rural area in Miri, Sarawak. The school has limited computer resources. Due to the geographical constrains, we conducted the evaluation in three sessions.

From Abnett C. et al. [11], we have learned that grouping students based on gender produces different results. Therefore, we were keen to observe the evaluation results based on such grouping to investigate whether gender affects the outcome of the results for Malaysian students. With that, we separated 12 students into 3 groups with one group comprising all boys (Group 1), another group consisting of all girls (Group 2) and the third group is a gender-balanced group with a mixture of 2 boys and 2 girls (Group 3). The members in the group are randomly selected by the researchers. The students have a basic level of Bahasa Malaysia literacy. The literacy level among the students is graded by their teachers.

The 12 students will be selected with a balance of 6 boys and 6 girls. With only 3 laptops and 12 mice available, we can only test with only 12 students at a time, with 4 students per laptop. Each of the tests was carried out in three separate visits. The itinerary of the visits is shown in Table 1 . We have set up our experiment as detailed below.

The instruments for the testing are:

- Paper-based questionnaires for pret and post-tests

- The Rimballmu system

- A video recorder to record the interaction among students
TABLE I.

AGENDA OF EACH VISIT IN TESTING THE TEACHING AND LEARNING ASPECTS OF RIMBAILMU

\begin{tabular}{|l|l|}
\hline Trip 1 & $\begin{array}{l}\text { 5min briefing to headmaster } \\
\text { 5min ice breaking } \\
\text { 15min pre test } \\
\text { 20min training on basic interaction in Rimbailmu } \\
\text { *each group will take turns to try out the system } \\
\text { (dragging, key in, merging)- observe their } \\
\text { interactions } \\
\text { 50min on playing with the system (3 computers } \\
\text { have been allocated- 12 students together) } \\
\text { 10min discussion with the students }\end{array}$ \\
\hline Trip 2 & $\begin{array}{l}\text { Testing the system with different setups } \\
\text { Boy group formation } \\
\text { Girl group formation } \\
\text { Mixed group formation }\end{array}$ \\
\hline Trip 3 & $\begin{array}{l}\text { Evaluate the use of Rimballmu in teaching and } \\
\text { learning in after school programmes } \\
\text { Post test- 15 minutes } \\
\text { Interview the students }\end{array}$ \\
\hline
\end{tabular}

- Researcher's observation

- Questionnaires/interview- usability study

- Screen capture software to periodically capture the students' interactions periodically

To begin with the experiment, twelve students were given a paper-based pre-test questionnaire with 20 questions. They were then given a short 10-minute training session to familiarize themselves with the MultiPoint environment. Upon completion of the training, the students proceeded with the tutorial sessions where they performed a series of exercises in Rimballmu. They had to answer 20 questions, and some questions were taken from the pre-test. After that, a post-test was immediately given to them. The post-test consisted of same questions like the pre-test. Teachers' intervention was prohibited during the testing. Meanwhile, the researchers were there to provide technical assistance.

We present the qualitative analysis of the experiment in this paper. Figures 10 and 11 show the photo during the experiments in the semi-urban school near Kota Samarahan. From the photo, we observe that students were so excited to get involved in the experiment and had a fun time in using Rimballmu.

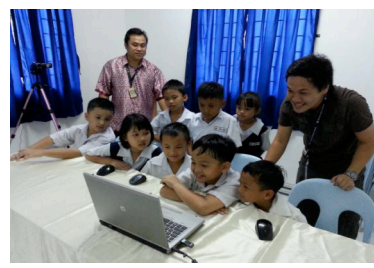

Figure 10. Students were excited during the training session
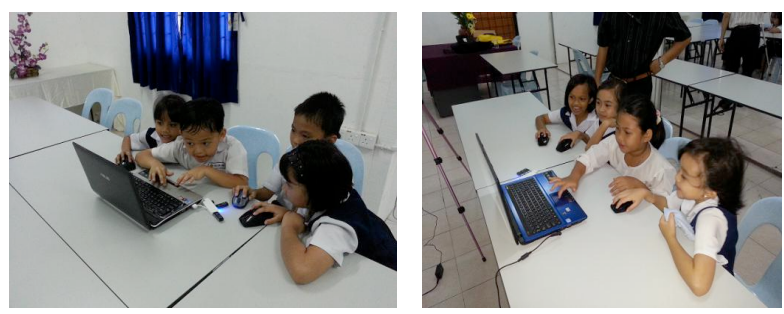

Figure 11. Mixed group and girl group using Rimballmu 
TABLE II.

RESULTS RIMBAILMU

\begin{tabular}{|l|l|l|l|}
\hline Issues/Group of distribution & Boy group & Girl group & Mixed group \\
\hline $\begin{array}{l}\text { Good students instruct the struggling } \\
\text { students on how to use the system so that } \\
\text { no one is left behind. }\end{array}$ & $\begin{array}{l}\text { No. The good } \\
\text { student took over } \\
\text { the control and } \\
\text { mouse. }\end{array}$ & Yes & Yes \\
\hline $\begin{array}{l}\text { Children would get too involved in the } \\
\text { racing aspect of the game and not focus as } \\
\text { much on getting the correct answer. }\end{array}$ & Yes & No & No \\
\hline $\begin{array}{l}\text { Children responded well to the mouse } \\
\text { control mechanism and had little trouble } \\
\text { understanding how to use the mouse. }\end{array}$ & Yes & Yes & Yes \\
\hline $\begin{array}{l}\text { Children are confused by multiple cursors } \\
\text { on screen }\end{array}$ & No & No & No \\
\hline $\begin{array}{l}\text { The split screen setup did not draw } \\
\text { childrens's attention away from their } \\
\text { own section of the screen }\end{array}$ & Yes & Yes & Yes \\
\hline $\begin{array}{l}\text { Children were able to accomplish the tasks } \\
\text { given }\end{array}$ & No & No \\
\hline $\begin{array}{l}\text { The students immediately understood the } \\
\text { U commands and } \\
\text { utilized them in the free play time at the } \\
\text { end. }\end{array}$ & $\begin{array}{l}\text { No, required } \\
\text { training }\end{array}$ & $\begin{array}{l}\text { No, required } \\
\text { training }\end{array}$ & No, required training \\
\hline $\begin{array}{l}\text { Continue discussion on other topics after } \\
\text { each activity or at the end of the test. }\end{array}$ & No & Yes & No \\
\hline Discussion of the answer during exercises & No & Yes & Yes \\
\hline
\end{tabular}

Table 2 shows one of the evaluation results from the observations at one primary school. In general, we reveal the potential usage of the Rimballmu into different perspectives. Apart from having similar beneifts to SSD technlogy as discussed in [25], Rimballmu is able to stimulate the collaboration between different genders. It is also a technology to engage students while being a tool for group and individual assessment, a tool to facilitate leadership skills and is fun to use. Rimballmu also allows ease of lab management and control, enables the novice to learn computers, promotes membership in collaboration learning and finally provides an environment for task accomplishment with minimum teacher intervention. We can further elaborate on the use of Rimballmu in the following.

\section{A. Collaboration patterns among different genders in both schools}

Our observation results show that the boy group had the least collaboration. They were less cooperative, passive and were only focused in completing their tasks individually. They were less enthusiastic and required continuous encouragement to propel them to complete the tasks. One male student was not serious in the activities and was not serious about his mouse click actions. This posed as a problem especially when the activity requires all of the team members to complete the tasks before they could proceed to the next level. His answers were incorrect due to the random clicking. This had disrupted the activities and had affected the state of mind of other team members. Some members were agitated and impatient, which drove them to snatch the mouse from him and complete the activity for him. Apart from that, another male student was losing interest when there were too many questions to answer. Constant motivation was required to push him to complete his tasks.

Different results were obtained for the girl group. They exhibited the followers' behavior. When the activity involved answering the same question, they would just follow the one who knew the answer to the particular question. When the activity required them to collaborate, they were very helpful guiding each other on where to click, whose turn to click and so on. With the activities that presented different sets of questions for each player, they would automatically help the other team members who were struggling with the questions after completing their own questions. In the team, there was a girl who could not properly operate the mouse. The others would patiently help her. Although this group was very well behaved, they relied heavily on each other and they were not concerned with their own grades. Therefore, the learning objectives of some activities were not achieved.

For the group setting which involved a balanced mixture of two boys and two girls, it was observed that the boys behaved better when they had to cooperate with the girls. During the testing, one boy from the group was very competitive and was not willing to help the others. He would just patiently wait for the others to finish their questions without providing any assistance. However, when collaboration was required, they would engage in discussions to complete the activities. They were less reliant on each other and would attempt to answer the questions independently if the questions were similar types. Hence, the students were able to achieve the learning goals for every designed activity.

From our observations, we can conclude that the group setting with the mixture of both genders performed better. They were able to achieve the following objectives: Selflearning, Peer Learning and Collaborative Learning.

\section{B. Shared single display -technology for engagement}

Our SSD has resulted in overall increased engagement, even for students without a mouse. All the students were thrilled to use the mouse in front of a laptop or monitor. The approach enlivens the learning process for these students. Laughter and occasional giggles could be heard from different groups during the testing phase. Discussions among the students were carried out during the activities and continued after the activities. Some of the students were very eager to know the answer right after the activities. However, the engagement declined with time when the students could not solve the given tasks. To continuously engage the students, our role was to encourage the students when necessary, giving them hints and guidance to the answers. It was interesting to see that some students would intervene in other groups to express his/her opinion or to give instructions during the activities (An example scenario is shown in Figure 12).
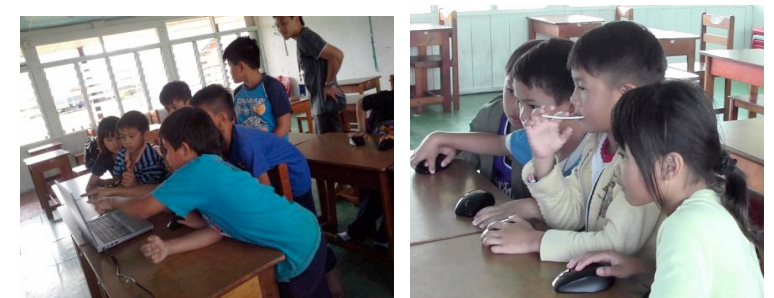

Figure 12. Engaging of students through Rimballmu

\section{Shared single display application- group and individual assessment tool}

SSD can be a useful tool for instructional design. It can be used to understand the learning style among the group of students or individual students. In Rimballmu, we designed our exercises based on a pool of questions with different bands.

The questions provided are based on three bands (band 1 , band 2 and band 3 ). It is worthwhile to note that most of the students could not complete the last two activities. We believe that this is caused by the insufficient time frame given. 
In one activity, we tested on visual memory ability among students. In this activity, the students needed to view the object and recall the correct answer. From our observations, this is what the students are good at, either in a group or as individuals. The students can easily recall the answer correctly. However, when it comes to sentences, the students were unable to apply or map the correct object to the sentences. But, they were able to read the sentences. Figure 13 (top) shows an example of a multiple choice question involving a given image. The students did not exhibit any problems in this activity. On the other hand, Figure 13 (bottom) shows a multiple choice question using sentences and the students did poorly on it. This applied to both, group and individual students.

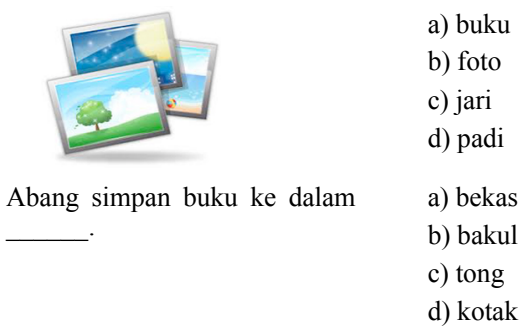

Figure 13. Top: Question type that students are good at - Bottom: Questions the students are poor at

\section{Dominance/ Leadership skill}

Domination was observed in groups during the testing. Every student in a team was required to complete the questions in order to proceed to the next activity. Some activities required the students to answer correctly, some do not. This mixed design established a leadership presence in the group.

From our observation, the leader would give instructions to the team members. The dominant student will either help the team members to complete the question or instruct them to answer the question. For example, in group 2, a dominant student gave a directive order to her friend to click on a particular answer via instructions such as "Click that answer!" "The answer is there" "You have not finished it, click on this answer". Similar behavior occurred in the mixed group. However, group 1 consisting of all boys did not exert a dominant presence. Instead, they were very excited in the game and were engrossed in trying to answer the given questions.

The strong assertive behaviour projected by some of the students exhibit the presence of leadership skills. It is interesting to notice that the strengths and weaknesses that existed in the group were a complement to each other. The dominant students would gladly help the struggling students for the benefit of the group. The downside of this is that the assertive ones would also stifle the weaker ones. For example, when frustrated, these leaders would take over the mouse control and answer the question on behalf of the weaker members. Negative attitudes were also observed in some of the students by refusing to collaborate and to help others.

\section{E. Play and fun}

Computer aided learning is notable for the impact it has on learning, making the process fun and engaging while creating a learner-centric environment for students (Figure
14). Towards achieving the same goal, Rimballmu positively immerses the students in the learning process and triggers active participation among them. Minimum training was required to help the students familiarize themselves with the interface and interaction with the system. Once the training has completed, the students were able to proceed with the activities with minimum guidance. There were instances where a student was too anxious and occupied with progressing to the next activity that he hastily completed the questions without getting them right.

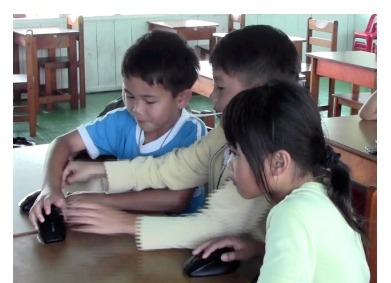

Figure 14. Student having fun to playing with Rimballmu as well as exchanging the mouse.

\section{Play and fun Ease of lab management or control}

\section{$F$. Ease of lab management or control}

In terms of operational and maintenance cost, the Rimballmu is economical and cost effective in the support of multi-users. In this situation where computer facilities are limited, it reduces the contention among students to use the computer. The students were able to behave well when using a single computer without any arguments. They could easily adapt and accustom themselves to multiple mice with multiple cursors on the display. With Rimballmu, we can accommodate 12 students on three laptops. This can reduce the licensing cost, computer storage space usage and maintenance of the number of computers in the long run.

\section{G. Rimballmu as a tool for basic ICT}

Rimballmu can become a tool to enable the novice to learn computers. During the testing, we identified some students who were first time computer users users. Albeit that, they can easily catch up and perform the activities in Rimballmu. We foresee that the interaction among the group has promoted the sharing of ICT knowledge among the students. It happens that students are talked about the use of computer, keyboard, and mouse during the testing.

\section{H. Rimballmu-Promoting membership in collaborative learning}

Group formation is not an easy task. Enabling a group to successfully work together involves several factors, which can range from environment, purpose, communication, membership, process and structure and resources [10]. The students were allocated a mouse each, giving them a perception of ownership and responsibility. With that, a sense of community is formed, where interdependence among each other is established by doing what is expected of them as a subset of larger group. By assigning an individual workspace to each student, it creates perceived control as part of the team to contribute to the success scenario. Hence, Rimballmu is able to create a membership identify to allow the group to work together successfully. 


\section{Effect of gender on task accomplishment}

As previously mentioned, different group settings based on gender had created different dynamics in the groups. We further analyse tasks accomplishment among different genders. It is interesting to note that the mixed group was the only group that could complete the given activities within the allocated time, whereas the single gender groups (groups 1 and 2) were unable to finish. For the boys' group, the main reason was due to the reluctance to cooperate. The lack of social bonding was the cause of it as they were arguing most of time when they failed to answer the questions. They were not persistent and gave up easily. On the contrary, the female group was caught up with discussing or gossiping. They did not pay attention to the time and thus, could not complete the given tasks.

\section{DISCUSSION}

Rimballmu is feasible as an education supported tool for resource constrainted environments. We successfully conducted the evaluation with two primary schools, one for a semi-urban school, and another for a rural school in Sarawak. Some challenges and opportunities were identified from the results of this research. The challenges are derived based on the technical difficulty on current multi mice technology. Meanwhile, opportunities are built upon the factors that drive the successful collaborative works [10]. The research challenges and opportunities of this research are described in the following subsectons.

\section{A. Technical challenges}

Developing SSD applications is no a straightforward processes. It takes a time to find a solution in handling the multi-mice events. To date, the only open source multimice development kit is from the Microsoft MultiPoint SDK [22], which was primarily written to be programmed in Visual C\#, an object-oriented programming language developed as part of the .NET platform. This posed quite a challenge for developers who wish to develop their MultiPoint application with different programming languages. Without the SDK, the MultiPoint framework and components will have to be coded out by the developer.

There is a known challenge when dealing with methods in Adobe Flash's Action-Script language, such as click events for standard buttons, which rely on mouse events from the operating system. The problem comes when the native events are not recognized because of the emulated cursors of $\mathrm{C} \#$ being a non-operating system cursor [12].

\section{B. Opportunities}

Studies of groupware use in understanding student learning styles have been discussed in Becker et. al., [1]. In [1], groupware is used to identify a group of students who are good in virtual learning styles and verbal learning styles. From our observations, our students are good in recalling objects but poor at remembering sentences. They able to recognize the objects and read sentences, but are not comfortable building or completing sentences. Hence, constructivism learning should be considered in schools. However, is learning taking place in Rimballmu? From our observation, students tend to discuss the answer during the exercises. They show difference in performance among different genders. More work is needed to conduct an empirical study on the usage of Rimballmu as a learning tool through pre and post-tests. Also, we can conduct a study on Rimballmu for learning retention over period as discussed in [19].

Dominance occurs when working using groupware [2]. They state that dominance gets stronger with strong collaborative design. We foresee dominance as something that can foster leadership in a team. For example, there is a quiet student who is interested to guide the other students when their team members do not answer the question correctly. He/She tried to tell them the right answer most of the time. But he/she faces problem to attract their attention even though persisting on it. From the survey by [2], too much dominance is not healthy to the group. However, how to balance between dominance and collaboration is worth further exploration.

Meanwhile, balancing playing and learning is another issue that needs to be further explored. When we start to develop the SSD application, our first idea was how to develop a collaborative or multiplayer game. We have related the SSD application as another platform for games. Hence, the works are focusing on graphic design and the games' logic. Based on the feedbacsk from the participants in R\&D expo and Rimballmu workshop, most people are interested on how to control and manage Rimballmu to improve learning in students. For the teacher, and teacher trainers, they are interested in how to customize the interaction activities, answers, records, languages and how learning is carried out. This is more useful to them as compared to having games alone. This led us towards this direction recently. We are working on an SSD-based authoring tool, which allows the teacher to customize RimbaIlmu according to their needs.

We reveal some of the potential experiments of Rimballmu in the previous description. Although we managed to develop Rimballmu as a SSD application, there are lots of development issues that need to be dealt with. Those issues have yet to be resolved. The current version of Rimballmu is only able to support four players within a SSD. During the execution of RimbaIlmu, students will interact with 9 different interaction designs within a particular exercise. The students are situated within their own working region for a set amount of time, or having a single region for some exercises. There are some technical issues that need to be considered as well, such as how effective the interaction design is with the growing number of users? How to provide appropriate feedback concerning simultaneous attempts to the SSD? [5]. One possible solution is to introduce individual audio channels so that each user receives sound from a private audio channel [9] when working in a SSD.

Also, other design consideration like exploring different multiple mouse text-entry techniques with respect to the reduced screen space and promote the speed in handling the simulatenous entries by users. Work has been done to study the multiple mouse text entry technique within a SSD like projection [7]. Since power is an issue, we can only deploy laptops or small screen computers. Hence, the issue of whether the proposed multiple mouse text-entry technique is suitable for small screens is worth exploring. Other studies such as how to partition the workspace for a single display groupware, is also worth investigating [8] and the adoption of patterns in designing the groupware [16][17] are worth to further explore. 


\section{CONCLUSION}

This paper introduces the Single Shared Display (SSD) technology installed with Single Display Groupware (SDG). In tandem with the sole purpose of this project within the context specified, the success criteria have been identified as follows:

Engagement: the technology introduced must be tied to the community's needs. Failing to do so will impede the success of the project. Engaging the community in the project development cultivates a sense of belonging. A close cooperation between the developers and the community is important to tailor the system to suit their needs.

Fun: It is important to deliver a system that is simple, user-friendly yet engaging. A complex system will demotivate the community as they are not technologically savvy, causing them to shy away from using the system. Being fun and entertaining are the main qualities to include as an encouragement for them to continuously use the system.

Low funding and low maintenance: Limited financial resources are a major drawback causing an insufficient providence of computer facilities, causing students to share computers. It is impossible to provide regular technical support and maintenance as the area is difficult to access.

Sustainability: The viability and sustainability of this project in the long run is a major issue to consider especially when the funds are depleted. Alternative solutions will have to be considered to deal with this issue.

We present the qualitative analysis in this paper. From the observation, we conclude that Rimballmu is able to stimulate the collaboration between different genders. It is a technology to engage students as a tool for group and individual assessment, a tool to facilitate leadership skills, a fun tool to play with. Rimballmu also allows ease of lab management and control, enables the novice to learn computers and promotes membership in collaboration learning and finally provide environment for task accomplishment with minumum teacher intervention. Consequently, SSD technology is feasible and useful to resource constrained environment and useful to the community.

\section{REFERENCES}

[1] D. Becker and M. Dwyer, M., "The impact of student verbal/visual learning style preference on implementing groupware in the classroom", Journal of Asynchronous Learning Networks 2(2), 61-69. Retrieved from http://www.aln.org/publications/jaln/index.as, 1998.

[2] C. Tseng, S. Garg, H. Underwood, L. Findlater, R. Anderson, and J. Pal., "Examining emergent dominance patterns in multiple input based educational systems", In Interaction Design for International Development, 2010

[3] U. Pawar, J. Pal, K. Toyoma, "Multiple Mice for Computers in Education in Developing Countries", ICTD, pp. 64-71, 2006.

[4] C. Alcoholado, N. Nussbaum, A. Tagle, F. Gomez, F. Denardin, H. Susaeta, M. Villalta, and K. Toyama, "One Mouse per child: interpersonal computer for individual arithmetic practice", Journal of Comptuer Assisted learning, 2011.

[5] N. Moraveji, K. Inkpen, E. Cutrell and R. Balakrishnan, "A mischief of mice: examining children's performance in single display groupware systems with 1 to 32 mice", in Proceedings of the 27th international conference on human factors in computing systems, CHI '09, pp. 2157-2166, New York, NY: ACM, 2009.

[6] A. Gupta, P. Shekhar, N. Samdaria, M. Jain and J. Pal, "DISHA: Multiple mice in narrative content-based computer aided learning for children", in Proceedings of IDID, BCS, India, 2010.

[7] S. Amershi, M. Morris, N. Moraveji, R. Balakrishnan and K. Toyama, "Multiple mouse text entry for single-display groupware", in Proceeding of the ACM Conference on Computer
Supported Cooperative Work (CSCW), Savannah, Georgia, USA, 2010.

[8] E. Tse, J. Histon, S. D. Scott and S. Greenberg, "Avoiding Interference: How People Use Spatial Separation and Partitioning in SDG Workspaces", in proceeding of CSCW'04.

[9] M. R. Morris, D. Morris and T. Winograd, "Individual Audio Channels with Single Display Groupware: Effects on Communication and Task Strategy", in proceedings of CSCW 2004, pp. 242251.

[10] P. W. Mattessich and B. R. Monsey, "Collaboration: What makes it work", Saint Paul, MN: Amherst H. Wilder Foundation, 1992.

[11] C. Abnett, D. Stanton, H. Neale, and O'Malley, "The effect of multiple input devices on collaboration and gender issues", in Proceedings of European perspectives on computer-supported collaborative learning (EuroCSCL), pp. 29-36, Maastricht, the Netherlands, 2001.

[12] G. Nascimento, B. Moreira, A. Brandao, C. Ruff, and E. Clua, "Multi-user application using Microsoft multipoint and Adobe flash", in proceedings of SBGames, X Brazilian Symposium on Computer Games and Digital Entertainment, Salvador, 2011.

[13] R. Armando, M. Eduardo, C. Emilio, and A. Francisco, "Inexpensive 3D stereo for two users using a single display", Ibero-American, Symposium in Computer Graphics, SIACG, 2011.

[14] P. Lyle, C. Lueg, and T. Ugent, "Multi-cursor multi-user mobile interaction with a large shared display", in proceedings of the Austrlian Computer-Human Interaction Conference (OzCHI 2012), pp. 357-360.

[15] J. Stewart, B. Bederson, A. Druin, "Single Display Groupware: A model for co-present collaboration", in Human Factors in Computing Systems: CHI 99, pp. 286-293, ACM Press.

[16] C. WaiShiang, L. Sterling, and K. Taverter, "Task knowledge patterns reuse in multi agent system", in proceedings of the 13th International Conference on Principles and Practice of MultiAgent Systems,. Kolkata, India, 2010.

[17] C. WaiShiang and L. Sterling, "Analysis and classificatin of tas knowledge patterns", in workshop of European council of modelling and simulation. Kuala Lumpur, 2010.

[18] A.W. Yeo, F. S. Hazis, T. Zaman, P. Songan, and K. A. Hamid, "Telecentre Replication Initiative in Borneo Malaysia: The Coeri Experience", The Electronic Journal on Information Systems in Developing Countries, vol. 50, no. 3, pp. 1-15, 2011.

[19] U. Pawar, J. Pal, R. Gupta and K. Toyoma, "Multiple Mice for Retention Tasks in Disadvantaged Schools", CHI07, 1581-1590.

[20] AECT Definition and Terminology Committee, "The Definition of Educational Technology", Washington DC: AECT, June 1, 2004. Retrieved from Middle East Technical University Open Courseware http://ocw.metu.edu.tr/file.php/118/molenda definition.pdf

[21] SSB. Singh, "Integrating geography information system in teaching geography in Malaysian secondary smart schools", Education journal, 2(4), pp. 149-154, 2013. http://dx.doi.org/10.11648/j.edu.20130204.17

[22] Microsoft, Microsoft multipoint SDK. retrieved from https://www.microsoft.com/multipoint/mouse-sdk/

[23] N. Moraveji, K. Inkpen, E. Cutrell, and R. Balakrishnan, "A mischief of mice: examining children's performance in single display groupware systems with 1 to 32 mice", in Proceedings of the 27th international conference on human factors in computing systems. CHI '09, pp. 2157-2166, New York, NY: ACM, 2009.

[24] G. Zurita and M. Nussbaum, "Computer supported collaborative learning using wirelessly connected handheld computers", Computers and Education, vol 42, pp. 289-314, 2004 http://dx.doi.org/10.1016/j.compedu.2003.08.005

\section{AUTHORS}

WaiShiang C. is a senior lecturer from Universiti Malaysia Sarawak. He research interests are cognitive agent architecture, agent oriented simulation and collaborative learning and design.

Edwin Mit is a senior lecturer from Universiti Malaysia Sarawak. He research interests are formal method, software enigneering.

Marlene Lu is a lecturer from Swinburne University Sarawak. She research interest is multi agent technology.

This work was supported by ministry of education Malaysia Submitted 08 October 2014. Published as resubmitted by the authors 21 February 2015. 